\title{
Aplikasi Sensor Accelerometer pada Handphone Android sebagai Pencatat Getaran Gempabumi secara Online
}

\author{
Rio Riantana, ${ }^{*}$ Hanief Beta, ${ }^{\dagger}$ Waskita Cahya, ${ }^{\ddagger}$ dan Darsono ${ }^{\S}$ \\ Jurusan Fisika, Fakultas Matematika dan Ilmu Pengetahuan Alam, \\ Universitas Sebelas Maret \\ Jl. Ir. Sutami No.36 A Kentingan, Surakarta 57126
}

\begin{abstract}
Intisari
Tujuan penelitian ini adalah menciptakan metode pencatatan getaran gempabumi secara realtime menggunakan sensor accelerometer pada perangkat android. Metode yang digunakan adalah Cloud Computing karena praktis dan efisien. Perangkat android yang digunakan adalah Xiaomi 2 dengan prosesor Qualcomm Snapdragon 410 quad-core @ 1,2Ghz dengan jaringan 4G LTE, sensor gyroscop, accelerometer, GPS support AGPS dan GLONASS. Semua informasi yang diterima perangkat android di lapangan dikirim ke server secara realtime per sekon. Pada sistem monitoring disajikan grafik aktifitas getaran secara realtime, peta lokasi titik yang diamati, peta prediksi cuaca, peta kontur permukaan tanah, dan nilai magnitudo percepatan getaran tanah.
\end{abstract}

\begin{abstract}
The method used is Cloud Computing, that is more practical and efficient.The purpose is to create a method of recording vibrations of earthquakes in realtime using the accelerometer sensor on android device. Android device used is Xiaomi 2 with processor Qualcomm Snapdragon 410 quad-cores @ 1.2 GHz with support for 4G LTE networks, gyroscop sensor, accelerometer, GPS support AGPSand GLONASS. All information received by android devices in the field will be sent to server in realtime per second. The monitoring system presented graphs vibration activity in realtime, location maps observed point, weather prediction maps, contour maps of land surface, and value of the magnitude of the acceleration of ground vibrations.
\end{abstract}

KATA KUNCI: earthquake, accelerometer, android, cloud computing

\section{PENDAHULUAN}

Di era globalisasi seperti sekarang ini, pemahaman dan keahlian tentang teknologi sangat diperlukan. Teknologi pada era ini sudah sangat kompleks pengaplikasiannya. Pemanfaatannya sangat membantu dalam semua kegiatan manusia. Persaingan global menuntut akan penguasaan teknologi mutakhir. Keahlian dalam bidang teknologi akan mempermudah persaingan secara global.

Teknologi informasi diperlukan pada jaman sekarang, tidak hanya sekedar komunikasi antar manusia, tetapi juga untuk komunikasi antara manusia dengan alam sekitar. Sekarang telah banyak diciptakan teknologi untuk menganalisis berbagai macam gejala alam.

Karena banyaknya potensi bencana alam di Indonesia, khususnya gempabumi, maka pemerintah harus menyiapkan sistem pelacak gempabumi agar bencana gempabumi tidak memakan banyak korban. Sistem pelacak gempa yang sering digunakan adalah menggunakan seismograf yang dipasang pada titik-titik rawan bencana gempa.

\footnotetext{
*E-MAIL: rioriantana@yahoo.com

†E-MAIL: haniefbeta@gmail.com

‡E-MAIL: waskitacahya@gmail.com

$\S$ E-MAIL: onos.dar@gmail.com
}

Aplikasi sensor accelerometer pada handphone android sebagai pencatat gempabumi secara online ini menggunakan web server untuk menghimpun data dari pembacaan getaran di lapangan oleh handphone android secara real time. Sehingga data getaran dari semua handphone android dapat disimpan secara terstruktur dan dapat divisualisasikan menggunakan grafik pada web monitoring.

Jika ditinjau dari media yang memberitakan tentang maraknya pencurian seismograf (kompas.co.id, tempo.co dan republika.co.id ) dapat diperkirakan sistem ini akan menghemat biaya sampai $99 \%$ dari pengadaan seismograf biasa. Sehingga biaya yang dikeluarkan hanya $1 \%$ dari biaya sebelumnya. Tentunya ini akan sangat menguntungkan jika sistem ini dapat digunakan sebagai alternatif pengganti sistem yang sudah ada.

\section{TINJAUAN PUSTAKA}

\section{Seismometer dan akselerometer}

Seismometer merupakan alat yang dirancang untuk merekam atau mencatat gerakan tanah (bumi) dalam arah tertentu. Alat mekanik merekam pergerakan tanah yang diperkuat sedangkan alat elektromagnetik merespon terhadap kecepatan gerak tanah [1]. 
Akselerometer adalah perangkat yang berfungsi untuk mengukur akselerasi dengan tepat. Akselerasi tepat yang diukur dengan akselerometer belum tentu memiliki ketepatan koordinat (laju perubahan velositas). Sebaliknya, akselerometer melihat akselerasi terkait dengan fenomena berat yang dialami oleh massa uji pada kerangka acuan perangkat akselerometer. Sebagai contoh, akselerometer di permukaan bumi akan mengukur akselerasi $\mathrm{g}=9,81 \mathrm{~m} / \mathrm{s}^{2}$ lurus ke atas karena beratnya. Sebaliknya, akselerometer jatuh bebas atau di luar angkasa akan mengukur nol. Jenis akselerasi yang bisa diukur oleh akselerometer adalah akselerasi gaya gravitasi [2].

\section{Android}

Android adalah sistem operasi berbasis Linux yang dirancang untuk perangkat seluler layar sentuh seperti telepon pintar dan komputer tablet. Android awalnya dikembangkan oleh Android, Inc., dengan dukungan finansial dari Google, yang kemudian membelinya pada tahun 2005. Sistem operasi ini dirilis secara resmi pada tahun 2007, bersamaan dengan didirikannya Open Handset Alliance, konsorsium dari perusahaan-perusahaan perangkat keras, perangkat lunak, dan telekomunikasi yang bertujuan untuk memajukan standar terbuka perangkat seluler. Ponsel android pertama mulai dijual pada bulan Oktober 2008 [3].

\section{Sensor pada android}

Sebagian besar perangkat android memiliki sensor yang digunakan untuk mengukur gerak, orientasi, dan berbagai kondisi lingkungan. Sensor ini mampu memberikan data mentah dengan presisi dan akurasi yang tinggi, dan berguna untuk memantau pergerakan perangkat dalam tiga dimensi(tiga sumbu) atau posisi, atau memantau perubahan keadaan lingkungan di sekitar perangkat. Misalnya, sebuah permainan dapat membacaan perangkat sensor gravitasi untuk mengartikan gerakan pengguna perangkat, seperti kemiringan, digoyang, rotasi, atau ayunan. Demikian juga, aplikasi cuaca menggunakan perangkat sensor temperatur dan sensor kelembaban untuk menghitung dan menampilkan kelembaban, atau aplikasi jelajah mungkin menggunakan sensor medan magnetik bumi dan accelerometer untuk penunjuk kompas.

Platform android mendukung tiga kategori sensor:

1. Sensor gerak

Sensor ini mengukur gaya percepatan dan gaya rotasi pada tiga sumbu. Kategori ini meliputi kecepatan, sensor gravitasi, giroskop, dan sensor vektor rotasi.

2. Sensor lingkungan

Sensor ini mengukur berbagai parameter lingkungan, seperti temperatur dan tekanan udara sekitar perangkat, pencahayaan, dan kelembaban. Kategori ini termasuk barometer, fotometer, dan termometer.

3. Sensor posisi

Sensor ini mengukur posisi fisik perangkat. Kategori ini meliputi sensor orientasi dan magnetometer [4].

\section{Data akselerograf}

Data akselerograf digunakan untuk mengukur percepatan tanah dan perhitungan intensitas gempabumi, informasi ini bermanfaat dalam menunjang pembuatan peringatan dini tsunami. Jaringan akselerograf dipasang secara bersamaan dengan pemasangan jaringan seismograf (co-located).

Data akselerograf dikirim ke Pusat Gempa Nasional bersama-sama dengan data seismograf secara realtime. Namun untuk mengolah data ini perangkat lunak pendukung dan mekanisme pemindahan data yang bergabung dengan seismograf belum berjalan baik [1].

\section{Magnitudo}

Skala yang sering digunakan untuk menyatakan magnitudo gempa adalah skala Richter. Secara umum, magnitudo dapat dihitung menggunakan formula berikut:

$$
M=\log \frac{A}{T}+f(\Delta, h)+C_{S}+C_{R}
$$

dengan $\mathrm{M}$ adalah magnitudo, $\mathrm{A}$ adalah amplitudo gerakan tanah (dalam mikrometer), $\mathrm{T}$ adalah periode gelombang, $\Delta$ adalah jarak pusat gempa atau episenter, $\mathrm{h}$ adalah kedalaman gempa, $\mathrm{C}_{S}$, dan $\mathrm{C}_{R}$ adalah faktor koreksi yang bergantung pada kondisi lokal dan regional daerahnya [5].

\section{Jaringan sensor nirkabel}

Jaringan sensor nirkabel (wireless sensor network) merupakan suatu sensor pintar (smart sensor) yang mana pada masing-masing titik sensornya memiliki kemampuan untuk merasakan keadaan sekitarnya (sensing), serta memproses data yang diperoleh dan berkomunikasi, akan tetapi dikembangkan dalam skala yang besar serta dapat dihubungkan satu sama lain. Sehingga dapat melakukan suatu fungsi pengawasan (monitoring) secara terus menerus (real time) terhadap suatu lingkungan yang akan di sensing oleh jaringan sensor nirkabel tersebut secara kolektif. Jaringan sensor nirkabel merupakan generasi baru dari sistem sensor, walaupun masih terbatas pada kemampuan proses data dan terbatasnya pula bandwidth untuk melakukan komunikasi. Para peneliti telah mencoba mengembangkan beberapa protokol baru yang khusus didesain untuk jaringan sensor nirkabel, yang bersifat energy awareness. Fokus penelitian lebih kepada protokol routing, karena adanya perbedaan yang mendasar antara jaringan biasa dibandingkan dengan jaringan sensor (baik arsitekrur jaringan maupun aplikasi). Gambar 1 menunjukan perbandingan grafis protokol generik yang digunakan untuk mendeskripsikan jalur komunikasi didalam jaringan sensor nirkabel [6].

\section{METODE PENELITIAN}

Pengoperasian aplikasi sensor accelerometer pada handphone android sebagai pencatat gempabumi secara online ini 


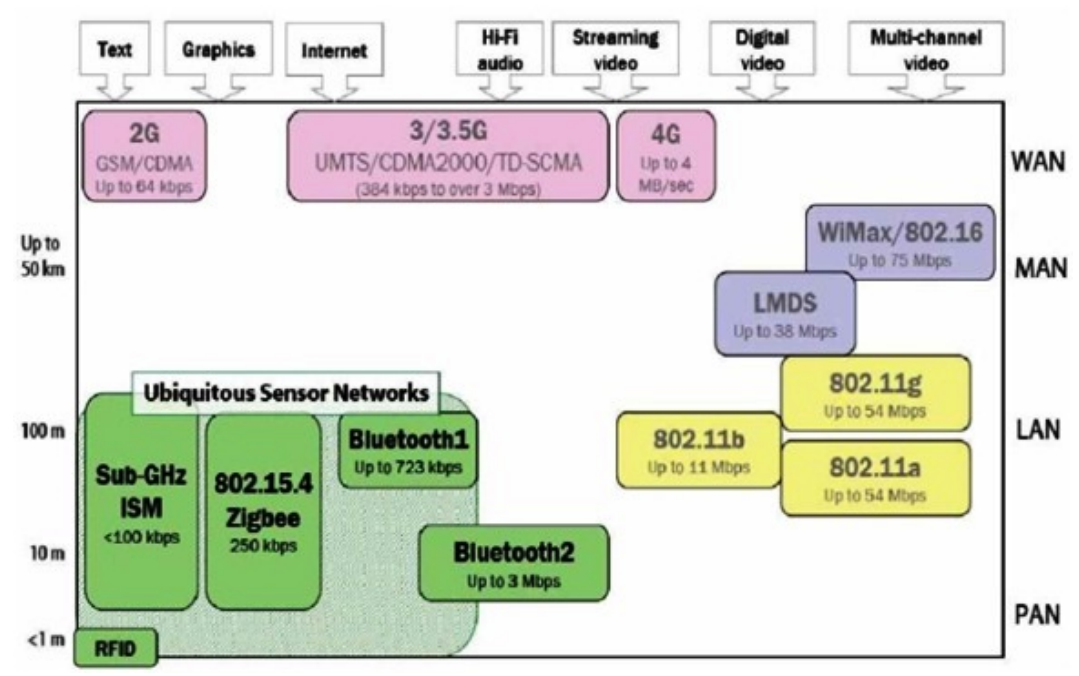

Gambar 1: Perbandingan protokol dan nirkabel.

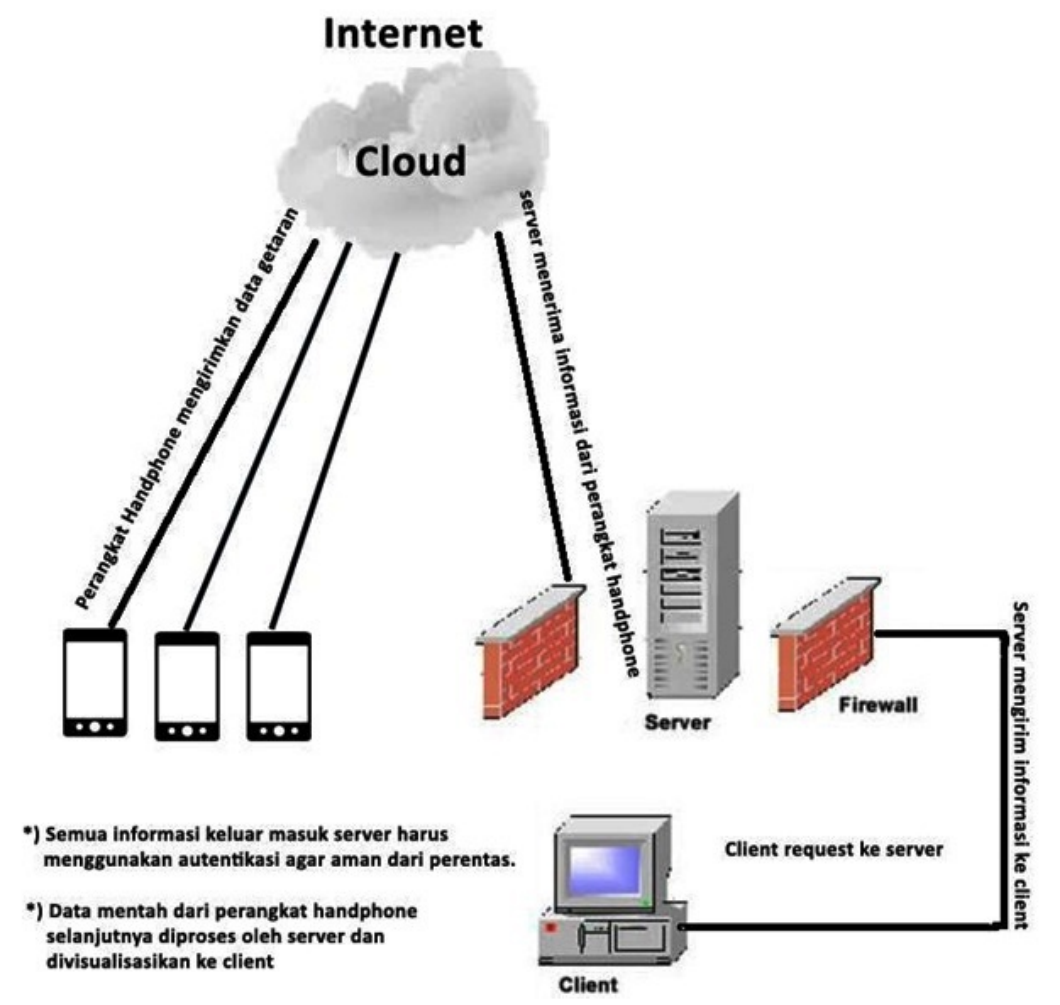

Gambar 2: Skema infrastruktur jaringan.

cukup sederhana. Untuk pengoperasian monitoring, hanya dengan dilakukan kontrol pada website yang telah diprogram untuk fungsi monitoring aktifitas getaran bumi. Website ini akan dipasang di hosting dengan tidak menggunakan domain, untuk menghindari atau meminimalisir penggunaan oleh pihak yang tidak berhak.

Metode yang digunakan adalah metode Cloud Computing yang dinilai lebih praktis dan efisien. Semua informasi yang diterima perangkat android di lapangan selanjutnya akan dikirim ke server secara real time per sekon. Data yang diterima server akan disimpan di dalam database. Data-data yang telah tersimpan akan diolah oleh server menjadi grafik getaran real time, informasi yang tersimpan antara lain informasi riwayat getaran secara grafik maupun nilai, informasi peta lokasi seismograf android, informasi tingkat kekuatan gempa, informasi potensi tsunami. Gambar 2 menggam- 


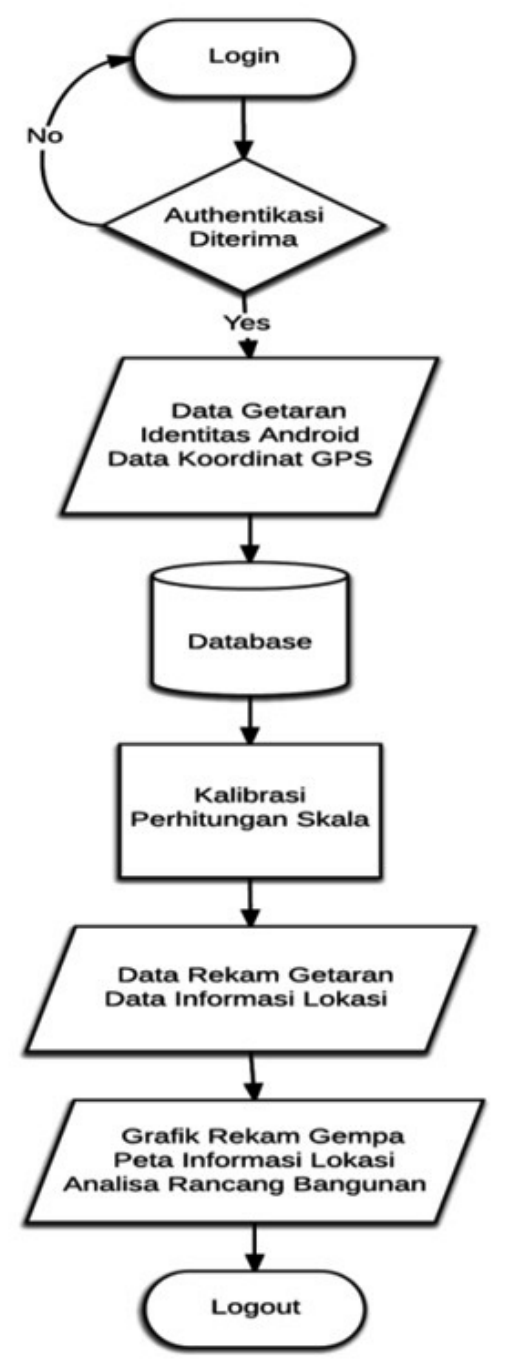

Gambar 3: Flow chart mekanisme sistem.

barkan skema infrastruktur jaringan sistem.

Pemrograman sistem ini dibagi menjadi tiga tahap, pertama adalah tahap pemrograman perangkat android yang berfungsi sebagai sensor utama getaran bumi, sensor ini disebut dengan sensor accelerometer. Untuk memprogram perangkat android digunakanlah program Eclipse dengan plug-in Android SDK. Perangkat diprogram agar dapat mengirimkan data perubahan getaran bumi setiap sekon ke server. Sehingga setiap sekon getaran yang terdeteksi dikirim di server dan dicatat di dalam database.

Tahap kedua adalah tahap persiapan server dan pemrograman website monitoring yang akan ditempatkan di server. Proses kedua ini membutuhkan waktu, tenaga, dan pengerjaan yang sangat kompleks. Perama-tama adalah merancang program interface monitoring agar mudah digunakan dan berjalan dengan baik. Pemrograman sistem monitoring ini berbasis website yang dibangun dengan bahasa pemrograman PHP. Website disetting untuk menerima informasi hasil pencatatan dari perangkat handphone lalu disimpan ke database. Setelah data tersimpan di database, maka data yang telah tersimpan

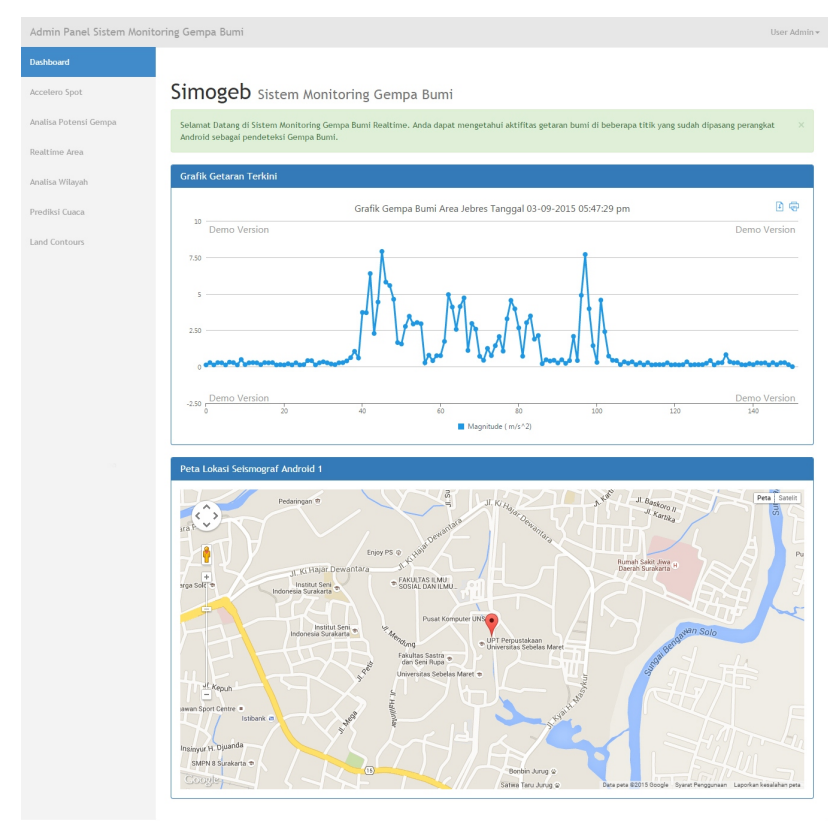

Gambar 4: Tampilan dashboard website.

tadi digunakan untuk menampilkan grafik aktifitas getaran bumi dengan fungsi skala getaran terhadap waktu. Sebelum data ditampilkan maka data dari database diproses terlebih dahulu dengan mencari fungsi agar hasil output diperoleh nilai magnitude di titik tersebut. Setelah proses konversi selesai maka data hasil konversi digunakan untuk menampilkan grafik. Selanjutnya, melengkapi fitur-fitur yang dibutuhkan oleh pengguna. Tahap ketiga adalah tahap analisis sistem dan debugging. Kegiatan ini dilakukan untuk mengetahui fiturfitur apa saja yang belum berjalan maksimal sehingga dapat memperkaya fitur dan mencegah atau menghilangkan resiko error program ketika dijalankan. Flowchart mekanisme sistem dapat dilihat pada Gambar 3.

Pemonitoringan akan lebih mudah karena dapat dipantau dari manapun karena sistemnya telah terpusat dan menggunakan jalur internet. Untuk kedepannya pada setiap titik juga akan ditambah fungsi-fungsi yang lain mengingat bahwa perangkat android mempunyai banyak sensor, maka sangat mungkin untuk mengoptimalkan semua sensor yang ada di dalamnya.

\section{HASIL DAN PEMBAHASAN}

Perangkat android yang digunakan adalah Xiaomi 2 dengan prosesor Qualcomm Snapdragon 410 quad-core @ 1,2Ghz dengan dukungan jaringan 4G LTE, sensor gyroscop, accelerometer, GPS support AGPS dan GLONASS, membuat perangkat ini pantas dipilih sebagai perangkat sensor pencatat getaran gempabumi. Dalam sistem monitoring gempabumi ini terdapat beberapa fitur yang dapat digunakan untuk menganalisis aktifitas seismik di beberapa titik sekaligus. Sehingga aktifitas seismik di semua lokasi dapat terpantau dengan baik. Gambar 4 menunjukan tampilan halaman 


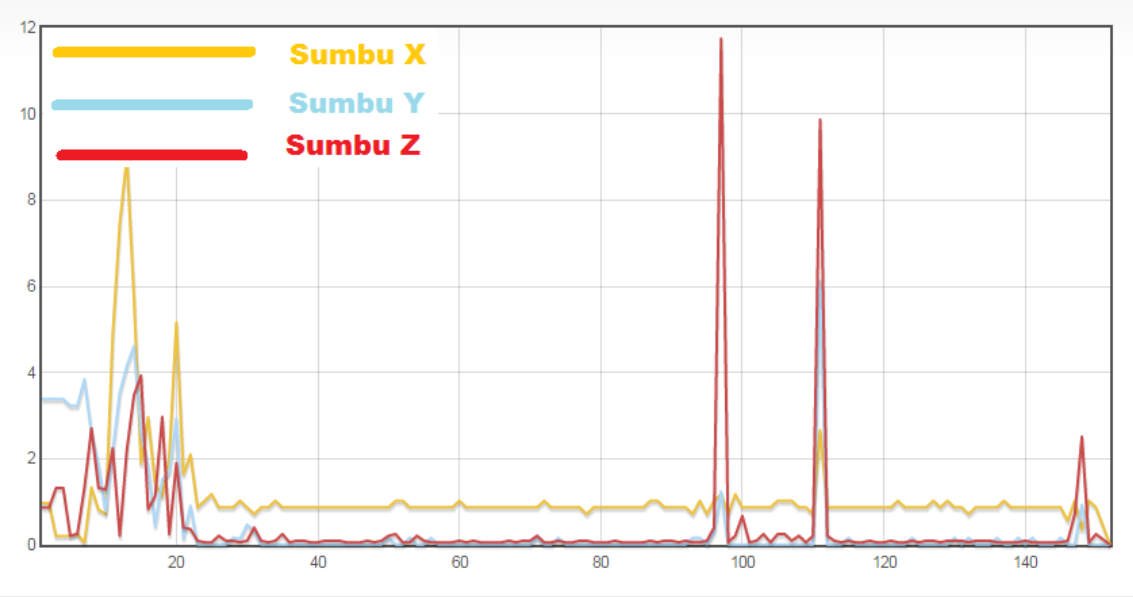

Gambar 5: Grafik realtime 3 sumbu pada website.

\begin{tabular}{|c|c|c|c|c|c|c|}
\hline No & Kode Lokasi & Koordinat & $x$ & $\mathbf{Y}$ & $z$ & Tanggal \\
\hline 1 & 1 & $-7.50969253,110.81237024$ & 0.15322891 & 0.15322894 & 0.15322876 & $08 / 03 / 201511: 25: 51$ \\
\hline 2 & 1 & $-7.50969253,110.81237024$ & 0.30645782 & 0.0 & 0.15322876 & $08 / 03 / 201511: 25: 52$ \\
\hline 3 & 1 & $-7.50969253,110.81237024$ & 0.15322891 & 0.0 & 0.15322876 & 08/03/2015 11:25:52 \\
\hline 4 & 1 & $-7.50969253,110.81237024$ & 0.0 & 0.0 & 0.15322876 & $08 / 03 / 201511: 25: 53$ \\
\hline 5 & 1 & $-7.50969253,110.81237024$ & 0.0 & 0.15322894 & 0.30645752 & 08/03/2015 11:25:53 \\
\hline 6 & 1 & $-7.50969253,110.81237024$ & 0.0 & 0.15322894 & 0.15322876 & $08 / 03 / 201511: 25: 54$ \\
\hline 7 & 1 & $-7.50969253,110.81237024$ & 0.15322891 & 0.0 & 0.0 & 08/03/2015 11:25:54 \\
\hline 8 & & $-7.50969763,110.81238765$ & 0.15322891 & 0.0 & 0.15322876 & 08/03/2015 11:25:54 \\
\hline 9 & & $-7.50969763,110.81238765$ & 0.15322891 & 0.0 & 0.15322876 & 08/03/2015 11:25:54 \\
\hline 10 & & $-7.50969763,110.81238765$ & 0.0 & 0.30645785 & 0.0 & 08/03/2015 11:25:55 \\
\hline
\end{tabular}

Gambar 6: Sample record database.

utama sistem monitoring gempabumi.

Salah satu fitur utama dari sistem monitoring gempabumi ini adalah adanya monitoring realtime, sehingga dapat diamati semua aktifitas seismik pada lokasi tersebut. Grafik disajikan secara animatif sesuai aktifitas seismik yang terjadi pada lokasi tersebut saat itu juga, ditunjukan pada Gambar 5.

Grafik menampilkan 3 sumbu utama yaitu sumbu X, sumbu $\mathrm{Y}$ dan sumbu $\mathrm{Z}$ dengan warna berbeda. Dari data yang dihimpun oleh database menunjukkan transmisi data diterima dengan baik. Program pada android mampu mengirim data dengan cepat dan tepat. Gambar 6 menunjukan contoh data yang tercatat di database server.

Program pada server mampu merespon request dari handphone android dengan interval 10 data per sekon per handphone dengan baik. Uji coba dilakukan menggunakan 2 handphone android sekaligus.

GPS berfungsi optimal dengan toleransi jarak sekitar \pm 3 meter. Koordinat yang dikirim oleh android ke server dapat ditampilkan dengan baik pada google maps yang telah di setting pada program di server ini yang ditunjukan oleh Gambar 7.

Untuk mengetahui tingkat kekuatan getaran maka digunakan metode magnitude dari 3 sumbu utama dengan persamaan,

$$
M=\sqrt{x^{2}+y^{2}+z^{2}}
$$

dengan $\mathrm{M}$ adalah resultan magnitudo getaran, $\mathrm{x}=$ getaran pada sumbu $x\left(\mathrm{~m} / \mathrm{s}^{2}\right), y=$ getaran pada sumbu y $\left(\mathrm{m} / \mathrm{s}^{2}\right), z=$

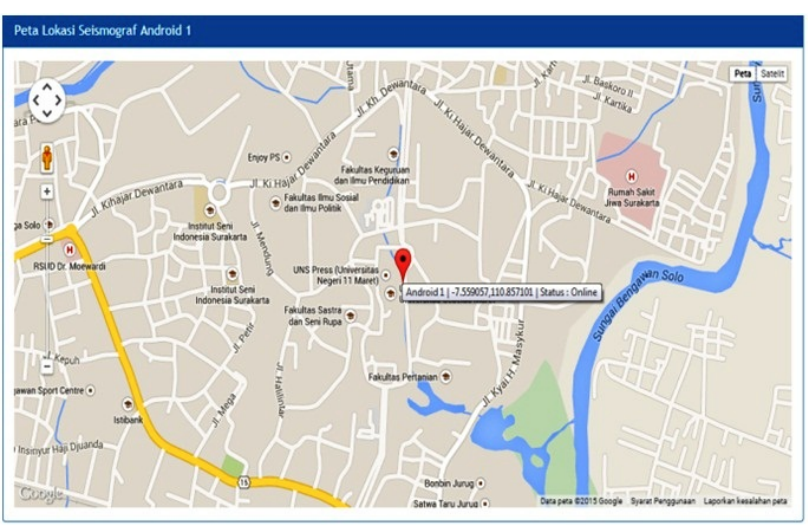

Gambar 7: Peta lokasi android pada website.

getaran pada sumbu z $\left(\mathrm{m} / \mathrm{s}^{2}\right)$.

Grafik dari magnitudo tersebut juga ditampilkan realtime namun tidak animatif untuk menjaga kestabilan aplikasi pada sisi pengguna. Grafik dari resultan magnitudo ditunjukan pada Gambar 8.

Pengujian data selama 20 sekon, didapatkan record pada server sebanyak 191 record, maka rata-rata data yang terkirim dan dicatat server adalah 9,55 record per sekon, maka prosentase data terkirim adalah 95,5\% dari harapan. Keakuratan waktu pengiriman data dari handphone dan pencatatan pada database sangat dipengaruhi oleh kondisi sambungan inter- 


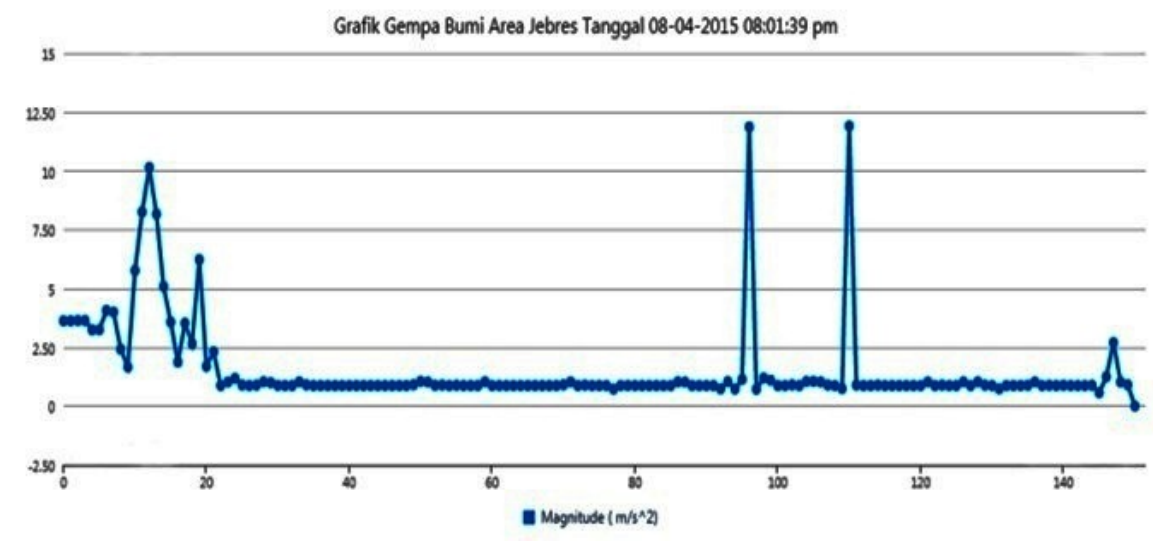

Gambar 8: Grafik resultan magnitude pada website.

net. Rata-rata besar data yang dikirim adalah 57 byte / record. Sehingga butuh minimal bandwidth internet sebesar 570 bps atau 0,57 Kbps pada android.

\section{SIMPULAN}

Sensor accelerometer pada handphone android dapat dijadikan referensi alat pencatat gempabumi pengganti seismograf untuk mencatat dan menghimpun data realtime. Metode telemetri yang digunakan dapat berjalan dengan baik. Keaku- ratan terkirimnya data ke server sebesar 95,5\% menunjukan bahwa peforma hardware dalam kondisi baik. Koneksi internet sangat mempengaruhi kecepatan proses pengiriman dari Hhandphone android dan pengolahan data pada server. Semua fitur dalam sistem monitoring bekerja dengan baik. GPS dan accelerometer bekerja dengan optimal. Penggunaan beberapa perangkat handphone android sekaligus dapat dilakukan. Diharapkan penggunaan perangkat dengan jumlah yang sangat besar dapat dilakukan dengan pembaruan hardware dan koneksi jaringan dengan lebih baik.
[1] A. Setiyaji, Analisis Kualitas Data Seismik 6 Stasiun Indonesia Menggunakan PQLX (FST UIN Syarif Hidayatullah, Jakarta, 2009).

[2] http://www.id.wikipedia.org/wiki/Accelerometer.

[3] http://www.id.wikipedia.org/wiki/Android (sistem operasi) .

[4] http://www.developer.android.com/guide/topics/sensors/sensors overview.html

[5] Hidayat, Usep, Andi, Perancangan Pengukur Magnitudo Dan
Arah Gempa Menggunakan Sensor Accelerometer ADXL330 Melalui Telemetri (Teknik Komputer UNIKOM, Bandung, 2012).

[6] B.S. Wahyono, Sistem Deteksi Gempa Bumi Berbasis Jaringan Sensor Nirkabel, Tugas Akhir, Jurusan Teknik Elektro FTI-ITS, Surabaya 2008. 